Western University Scholarship@Western

Department of Economics Research Reports

Economics Working Papers Archive

1999

\title{
Team Incentives and Organizational Form
}

Al Slivinski

Follow this and additional works at: https://ir.lib.uwo.ca/economicsresrpt

Part of the Economics Commons

Citation of this paper:

Slivinski, Al. "Team Incentives and Organizational Form." Department of Economics Research Reports, 9916. London, ON:

Department of Economics, University of Western Ontario (1999). 


\title{
RESEARCH REPORT 9916
}

\section{Team Incentives and Organizational Form}

\author{
ECONOMICS REFEREPICE CENTRE \\ by \\ Al Slivinski $\quad$ MAR -82000
}

UNAVERSITY OF MESTERN ONTARFO

\section{November 1999}

\author{
Department of Economics \\ Social Science Centre \\ University of Western Ontario \\ London, Ontario, Canada \\ N6A 5C2 \\ econref@julian.uwo.ca
}




\title{
Team Incentives and Organizational Form
}

\author{
Al Slivinski ${ }^{1}$ \\ Department of Economics \\ University of Western Ontario \\ London, CANADA N6A 5C2 \\ aslivins@julian.uwo.ca
}

November 24, 1999

\footnotetext{
'Previous drafts of this paper were circulated and presented under the title 'Moral Hazard in Nonprofit Teams'. I thank Keith Acheson, David Andolfatto, Eleanor Brown, Ig Horstmann, Chantale LaCasse, Gerald Marschke, Preston McAfee, Peter Rangazas, Michael Smart, Lise Vesterlund, Jay Wilson and Ralph Winter for useful input at various stages in the development of this paper. Financial support from the Social Sciences and Humanities Research Council of Canada is gratefully acknowledged.
} 


\begin{abstract}
Conventional wisdom regarding nonprofit firms is that they are inefficient, due to the absence of a profit motive. However, the costs and product quality realized by profit-taking firms is determined by how well those firms deal with a host of internal incentive and information issues. A similar approach to the study of nonprofit organizations has not been attempted. This paper undertakes such an investigation, centered on the problem of providing incentives for members of a team to provide efficient effort . Holmstrom(1982) showed that the introduction of a budget-breaker, or principal, into a team allowed for the provision of such incentives where it would otherwise be impossible. A similar result obtains for a nonprofit team, but the role of principal differs from that found in profit-taking teams. It is shown that any of; donors, government regulators, or Trustees can fulfill this role in a nonprofit team. One implication of this is that nonprofit firms may indeed pay employees less than otherwise identical employees filling identical posts in profit-taking firms.
\end{abstract}




\section{Introduction}

Nonprofit organizations are a large and growing part of most developed economies, particularly that of the US. The total resources available to the nonprofit sector in the US, excluding the value of volunteer labor, was $\$ 508$ billion in 1992 . However, only $18.4 \%$ of these resources came from private monetary donations. The rest consisted of government funding and earned revenues from fees, dues and investments. Indeed, these 'earned revenues' are the single largest source of income for the nonprofit sector, making up $50 \%$ of total revenues in 1992, and of all the sub-sectors into which nonprofits are divided, only that of Religious organizations received more than half its revenues from private donations. ${ }^{1}$ It is clear from this that 'nonprofit' is not synonymous with 'charitable'. Most nonprofit organizations can be considered enterprises that operate technologies, just as in the standard model of profit-taking firms. Further, many nonprofits operate in fields in which they co-exist with taxable, profit-taking firms. Nonprofit hospitals comprised $91 \%$ of 'General medical and surgical hospitals' in the US in 1987, as measured by revenues, while only $20 \%$ of kidney dialysis centers are nonprofit organizations. Nonprofit enterprises made up $43 \%$ of the child daycare market in the same year, $35 \%$ of sporting and recreational camps, $11 \%$ of vocational schools, and $37 \%$ of research, development and testing services. ${ }^{2}$

Casual economic thinking about nonprofit organizations typically includes two basic tenets. Because such firms face no pressure from any residual claimants to earn profits, they are expected to be inefficient in various ways. They are expected to exhibit higher costs, grant more unproductive managerial perks, and show less interest in satisfied customers, than do otherwise similar profit-taking firms. ${ }^{3}$ Secondly, it is thought that they attract 'idealistic' individuals to themselves, employees who willingly work for less than they could earn in comparable profit-taking firms. ${ }^{4}$ However, the evidence on cost and quality differences between for-profit and nonprofit organizations is mixed, at best, as is the evidence on differentials in compensation. ${ }^{5}$

\footnotetext{
${ }^{1}$ All of these statistics are taken from Independent Sector(1992).

2Source: U.S. Department of Commerce (1989).

${ }^{3}$ The best known statement of this view can be found in Alchian and Demsetz(1972).

${ }^{4}$ Evidence that employees of nonprofits earn less is found by Preston(1989), by Weisbrod(1982) for lawvers and by Roomkin and Weisbrod(1994) for top hospital executives.

${ }^{5}$ Rose-Ackerman(1996) summarizes a number of empirical studies on cost and quality differentials.
} 
From the perspective of firm theory, it is surprising that a belief in the relative inefficiency of nonprofit firms survives. It follows from a presumption that the profit motive is an important spur to efficiency, a presumption that has been questioned for modern corporations, with their separation of ownership from control, by writers going back to Berle and Means(1932). However, even if one grants this presumption, it does not follow that other organizational forms and entrepreneurial/managerial motivations might not also induce an incentive for organizations to operate at low cost and provide high quality. Part of the difficulty here lies in the fact that there is no generally accepted assumption regarding the motivations of those who found and manage nonprofit organizations. ${ }^{6}$ More fundamentally, however, modern research on the internal structure of profit-taking firms takes the position that the cost and quality realizations observed for them are a result of managers' and owners' struggles with a long list of incentive problems. Moral hazard, opportunism, adverse selection and other problems of asymmetric information are present in profit-making firms, and how well they are dealt with is taken to be a primary determinant of how (and what) such firms do. There is no reason to take a different view in thinking about nonprofit firms, yet very little work has been done on the internal incentive structures of nonprofit organizations. I know of no formal model of organizations which predicts the existence of the cost differentials for which the empirical studies cited above have been searching.

Any of the many incentive and information issues that have proven useful in understanding the behavior and internal structure of profit-taking firms might permit the development of predictions about differences between nonprofit and for-profit organizations. If nonprofit organizations deal with a different set of internal incentive problems than do profit-taking firms, or must deal with the same problems but in different ways, this has the potential to yield predictions about observable differences in the two types of firms. In this paper a model is developed in which the choice between these two organizational structures determines the constraints an organization faces in dealing with what is known as the team incentive problem.

The team incentive problem arises when a firm's realized output is dependent on the joint efforts of many members whose individual efforts cannot be separately observed. In such an environment, team members can

\footnotetext{
${ }^{6}$ The title (and content) of Dennis Young's 1983 study of nonprofit entrepreneurship, If not for profit, for what?, is indicative of this lack of consensus.
} 
be provided with incentives for providing effort that are functions only of jointly-generated team outcomes. Presumably, this incentive problem arises no less often in nonprofit organizations than it does in profit-taking firms. Further, a central result in the literature on team incentives due to Holmstrom(1982), asserts that in such an environment no team incentive scheme can provide incentives for the provision of efficient effort by team members. It is also known that the introduction of an agent known as a budget-breaker (I will adopt the neutral term 'principal' for this team member) does allow the firm to construct team-outcome based incentive schemes that induce efficient individual effort. However, the necessary characteristic this principal must exhibit is that he not provide any unobservable inputs into the team production process. The only members of a profit-taking firm with this characteristic are stockholders, and a fundamental difference between for-profit and nonprofit firms is that the latter cannot have stockholders. This suggests that the team incentive problem is a natural framework within which to look for differences in the efficiency of for-profit and nonprofit firms.

It is shown here that without the introduction of a principal, non-profit teams also cannot devise team-outcome based compensation schemes that provide incentives for efficient effort choices. Thus, the absence of stockholders who can play the role of principal appears to be a liability for the nonprofit form of organization. However, it is also shown that the introduction into the nonprofit firm of team members whose role is a variant of that played by stockholders in a profit-taking team allows for a solution to a nonprofit organization's team incentive problem. It is further argued that nonprofit organizations do include 'members' who can be viewed as playing that role. A corollary to this result is the prediction that (some) employees in nonprofit organizations will receive lower monetary compensation than do otherwise identical workers in otherwise identical jobs in a profit-taking firm.

The other way in which nonprofit firms are different is that they normally have a primary mission other than the generation of profit, of course. These organizations are then subject to various regulatory constraints not imposed on proprietary firms, the purpose of which is to insure the organization carries out this primary mission, since this mission is the justification for the special treatment granted to nonprofit organizations in tax codes and in the law. ${ }^{7}$ Such regulation may induce nonprofit firms to alter the internal al-

\footnotetext{
${ }^{7}$ There are several justifications for the tax treatment of nonprofit organizations, and considerable disagreement as to their relative merits. Brody $(1998)$ provides a discussion
} 
location of effort and compensation they realize. (If it does not, then the results stated above still apply, of course). This distortion of organizational goals is a two-edged sword. As with any such distortion, it means a regulated nonprofit firm is trying to implement second-best outcomes. However, this very fact may then make possible the construction of incentive schemes that induce the team effort choices that result in those outcomes. This is because the impossibility results cited above rely critically on the fact that the organization is trying to implement some first-best efficient outcome. If it is true that regulated nonprofit organizations can realize the second-best outcomes they desire without introducing a principal into the organization, then this has implications for the structure of such organizations.

This possibility is investigated here for two types of regulations commonly imposed on nonprofit organizations; prohibitions against 'excessive compensation' of team members, and constraints on the minimal amount of revenues that the organization must devote it its primary mission. In both cases I show that it is still true that no incentive system can induce the effort required for the organization to attain regulation-constrained second-best outcomes. Thus, regulated nonprofit organizations still must introduce principals if they wish to attain these outcomes.

The next section of the paper develops a general framework for the team incentive problem that includes both profit-taking (P-teams) and nonprofit (NP-teams) organizations as special cases. It is then shown that it is impossible to induce efficient effort choices using team-outcome incentive schemes in any of these teams, thus extending Holmstrom's (1982) result. The introduction of appropriate principals into each type of team is then analyzed, and shown to solve the problem in each case. However, because NP-teams cannot include stockholders, the role played by a principal in the two types of organizations must differ, as is the treatment of principals by the efficient-effort inducing compensation schemes. The possibility that NP-teams subject to regulation might not require principals is considered in the following section. Concluding remarks and a discussion of possible extensions of the analysis are presented in the last section.

from a legal perspective. 


\section{The Team Incentive Problem}

In the standard formulation of the team incentive problem [see Holmstrom(1982), Legros and Matthews (1993), Dutta and Radner(1993)] a team consists of $n$ individuals, indexed by $i=1, \ldots, n$. Each of them cares about the amount they have available to spend on private consumption, $x_{i}$, and about the amount of input they supply to the team, $e_{i}$. This latter variable is generally referred to as $i^{\prime} s$ effort. What is important about $e_{i}$ is that individuals prefer to supply less of it, all else equal, and that the amount supplied by each individual team member is unobservable, hence no member's compensation can be contingent on the vector $e=\left(e_{1}, \ldots, e_{n}\right)$. I assume that there exist minimum and maximum possible levels of $e_{i}$, and without loss of generality then assume that each $e_{i} \in[0,1]$. In this standard formulation, the payoff to team member $i$ is taken to be: $U_{i}\left(x_{i}, e_{i}\right)=u_{i}\left(x_{i}\right)-v_{i}\left(e_{i}\right)$.

A technology, $f()$, describes how the effort choices of the $n$ team members generate net revenues for the organization. I write $R=f(e)$, where the output, $R$, is taken to be the net revenue that is generated by these efforts. It is assumed that $f_{i} \equiv \partial f / \partial e_{i}>0, \partial^{2} f / \partial e_{i}^{2}=f_{i i}<0$, and that $R$ is observable. Team members may also supply other observable inputs to the team, such as hours spent working in the organization, or various kinds of non-human capital. If $l=\left(l_{1}, \ldots, l_{n}\right)$ is the vector of such inputs, one would write $R=f(e, l)$ and the $l_{i}$ might also enter into the payoff functions. In the analysis to follow it is assumed that the $l_{i}$ have all been contracted on, and are fixed throughout the analysis. ${ }^{8}$ Individuals in the team may have other sources of income, so that $x_{i}=w_{i}+z_{i}$, where $w_{i}$ consists of all the payments the individual receives which do not depend on the incentive contracts analyzed here. Since $w_{i}$ is taken to be fixed throughout the paper, it is simply ignored in what follows.

I extend this standard formulation by positing the existence of a second good, $z$, the provision of which may matter to team members. The nature of this good will be discussed below, but it is assumed that it is produced using only dollars, and the production function for $z$ is $z=k(y)$, where $y$ are simply the dollars devoted to it. Team member payoffs are now given

\footnotetext{
${ }^{8}$ The literature on multi-tasking [see Holmstrom and Milgrom(1991)] would suggest that when an agent supplies two inputs such as $e_{i}$ and $l_{i}$ here, it is sub-optimal for the firm to only provide incentives to supply the easily measurable input. Although it is clearly easier to do so, it induces the agent to under-supply the hard-to-measure input, which would be $e_{i}$ in the present context.
} 
by $\tilde{U}_{i}\left(x_{i}, e_{i}, z\right)=u_{i}\left(x_{i}\right)+\tilde{m}_{i}(z)-v_{i}\left(e_{i}\right)$, and letting $m_{i}(y) \equiv \tilde{m}_{i}(k(y))$, with $u_{i}^{\prime}, v_{i}^{\prime}, v_{i}^{\prime \prime}>0 \geq u_{i}^{\prime \prime}$,and $m_{i}^{\prime} \geq 0 \geq m_{i}^{\prime \prime}, I$ let $W_{i}\left(x_{i}, e_{i}, y\right)=u_{i}\left(x_{i}\right)+m_{i}(y)-$ $v_{i}\left(e_{i}\right)^{9}$

A team allocation is then a vector $a=(x, e, y)$, where $x=\left(x_{1}, \ldots, x_{n}\right)$, and I let $a_{i}=\left(x_{i}, e_{i}, y\right)$.

An allocation $a$ is feasible if $\sum_{i=1}^{n} x_{i}+y \leq f(e)$. Thus, the funds for the provision of $z$ must be generated by the efforts of the team. $a$ is efficient if it is feasible and there is no other feasible $a^{\prime}$ such that $W_{i}\left(a_{i}\right) \leq W_{i}\left(a_{i}^{\prime}\right)$ for all $i$, with at least one strict inequality.

Necessary conditions for an interior $a^{*}$ to be efficient are:

$$
\begin{gathered}
f_{i}^{\prime}\left(e^{*}\right) u_{i}^{\prime}\left(x_{i}^{*}\right)=v_{i}^{\prime}\left(e_{i}^{*}\right) \text { for } i=1,2, \ldots, n, \\
\sum_{i=1}^{n} \frac{m_{i}^{\prime}\left(y^{*}\right)}{u_{i}^{\prime}\left(x_{i}^{*}\right)}=1,
\end{gathered}
$$

and

$$
X^{*}+y^{*}=f\left(e^{*}\right) \equiv R^{*} \text {. }
$$

Conditions (1) are the same as those that are necessary for efficient effort in the standard team formulation, while (2) is a familiar Samuelsonian public goods condition. Note, however, that this latter condition encompasses only those within the team. The idea underlying this generalization of the static team problem is the following. A team is a collection of members whose efforts (in conjunction with other, observable, inputs) generate revenues net of the payments for those observable inputs. These net revenues can be used to provide direct, private consumption to team members and to provide a collective good from which team members may also get utility.

Whatever one may assume about the resolution of conflicting goals within a team, at minimum it is desirable that it attains an efficient allocation, $a$. Efficiency requires both that an appropriate set of efforts is chosen jointly by team members, and that the net revenues generated by the team are appropriately allocated among $x$ and $y$.

The team incentive problem is then as follows (see Holmstrom(1982)). Is it possible to devise a compensation scheme for team members which

\footnotetext{
${ }^{9}$ Holmstrom(1982) assumed the quasi-linear form $u_{i}\left(x_{i}\right)=x_{i}$, as does much of the rest of the literature.
} 
gives them the incentive to provide efficient effort levels, and which produces an efficient allocation of the net revenues generated by that effort? A compensation scheme is a set of agent compensation functions, $\sigma(\cdot)=$ $\left(\sigma_{1}(\cdot), \sigma_{2}(\cdot), \ldots, \sigma_{n}(\cdot)\right)$, and a function. $\theta(\cdot)$ that determines the level of $y$, each of which is a function only of net revenues, $R$. Such a vector of functions $\Gamma(\cdot)=(\sigma(\cdot), \theta(\cdot))$ will be referred to as an allocation scheme.

As in the standard team problem, it is assumed that team members simultaneously and non-cooperatively choose $e_{i}$ values, knowing the compensation scheme, $\Gamma$.

Any allocation scheme makes the payoff to each individual in the organization a function of this simultaneous choice of efforts:

$$
\mu_{i}\left(e_{i}, e_{-i}\right)=u_{i}\left[\sigma_{i}\left(f\left(e_{i}, e_{-i}\right)\right)\right]+m_{i}\left[\theta\left(f\left(e_{i}, e_{-i}\right)\right)\right]-v_{i}\left(e_{i}\right)
$$

Any $\Gamma$ therefore induces a normal form game with the team members as the players, the functions (4) as the payoff functions, and $[0,1]$ as each player's strategy set. The exact question then is whether there exists a $\Gamma$ which induces a game for which the allocation that results from a Nash equilibrium of that game is efficient. If $e^{n}$ is any Nash equilibrium effort profile of the game induced by some $\Gamma$, then it generates the allocation: $a^{n}=\left(x^{n}, e^{n}, y^{n}\right)=\left(\sigma\left(f\left(e^{n}\right)\right), e^{n}, \theta\left(f\left(e^{n}\right)\right)\right)$.

Certain restrictions are typically placed on the set of admissible $\Gamma$. First of all, it is assumed that there are limits on how much private consumption an individual can be left with by the scheme, and this is captured by requiring that:

$$
\text { for all } i \text { and all } R, \sigma_{i}(R) \geq \underline{x}_{i} .
$$

The lower bound may be negative, so this doesn't preclude penalties being imposed on team members in some situations, only that these penalties not be unbounded. Beyond this, Holmstrom's original analysis required that the simpler team compensation scheme consisting only of $\sigma$ satisfy a property called budget balance. That is, it must always allocate all of any net revenues generated by the team to the team members, since a $\Gamma$ that did otherwise would simply not be credible. The team itself must implement the scheme, and will be unwilling to simply throw away resources, ex-post, and of course will find it impossible to allocate revenues it does not have. This same reasoning in the present formulation implies that the credibility of any $\Gamma$ requires that it must satisfy: 


$$
\sum_{i=1}^{n} \sigma_{i}(R)+\theta(R) \equiv R
$$

Because there are two uses to which the team can put any $R$, guaranteeing the credibility of $\Gamma$ requires more than simply the absence of pure waste that is imposed by (6). Credibility requires that the 'contracted allocation' represented by any $\Gamma$ must be re-negotiation proof. That is, $\Gamma$ must be such that $\Gamma(R)$ specifies an ex-post efficient allocation of $R$ for every $R$.

Thus, $\Gamma$ is credible if and only if for all $R$, there exists no $\left(x^{\prime}, y^{\prime}\right) \neq \Gamma(R)$ such that;

$\sum_{i=1}^{n} x_{i}^{\prime}+y^{\prime} \leq R$, and

$V_{i}\left(x_{i}^{\prime}, y^{\prime}\right) \equiv u_{i}\left(x_{i}^{\prime}\right)+m_{i}\left(y^{\prime}\right) \geq u_{i}\left(\sigma_{i}(R)\right)+m_{i}(\theta(R)) \equiv V_{i}\left(\sigma_{i}(R), \theta(R)\right)$, for all $i$,with at least one strict inequality.

If $\Gamma(R)$ satisfies this for a given $R$, it will be said to be $R$-efficient, and credibility then requires $\Gamma$ to be $R$-efficient for all possible $R$.

A necessary condition for any $\Gamma(R)$ to be $R$-efficient if $\Gamma(R)$ is an interior allocation, is that;

$$
\sum_{i=1}^{n} \frac{m_{i}^{\prime}(\theta(R))}{u_{i}^{\prime}\left(\sigma_{i}(R)\right)}=1
$$

If this generalization of the team problem is to be useful in generating differences in the structure and/or behavior of profit-taking vs. nonprofit firms then it must, of course, encompass both types of organizations. The position taken here is that these two organizational forms are not technologically different. Both face the incentive problem formulated above, and the technologies that transform effort and other inputs into $R$ do not vary purely as a result of the organizational form adopted. The two types of organizations may also be dealt with differently in law and in the way they are taxed, and that may cause them to have different net-revenue generating capabilities. The goal here is to look for fundamental differences between for-profit and nonprofit organizations, partly as a necessary ingredient in analyzing any policy of differential tax or legal treatment.

Here, the difference is captured purely as one of a difference in tastes for members of the organization. The production of $z$ by the team using net revenues that have been diverted away from member compensation into $y$, is taken as a fundamental characteristic of nonprofit firms. Formally, only the preferences of those within any team distinguish the two types of teams. A for-profit team is simply one for which: 


$$
m_{i}^{\prime} \equiv 0, \text { for all } i
$$

If no one in the organization cares about anything other than private compensation and personal effort, then it is immediate that the only efficient allocations for the team are those in which $y=0$. Then, for any $\Gamma$ to be credible it is necessary and sufficient that $\theta(R) \equiv 0$, and that (6) holds. So when (8) holds, the team is faced with the standard incentive problem. Note that it is not necessary that all team members care positively about $y$ in order for the team problem to be different from this, however. If even one team member gets utility from the provision of $z$, then an efficient allocation may include $y>0$.

The universe of nonprofit organizations is highly diverse, encompassing pure charities like The Salvation Army, as well as hospitals, universities and primary schools, theatre companies and orchestras, museums, TV and radio stations and amateur sports leagues. So long as the organization involves a group of individuals whose effort is required to generate revenue, it is encompassed by the model above.

The analysis here therefore applies to pure charities that do their own fund-raising ${ }^{10}$, universities whose development offices raise funds and which also charge their patrons for educational services, museums, zoos and theatres that charge entry fees, operate gift shops, and often engage in other fundraising activities, as well as hospitals. Nonprofit social service and medical research organizations receive government and private foundation grants as a result of the joint lobbying and grantsmanship efforts of a team of employees, and many nonprofit organizations produce and sell goods and services in much the same way as do profit-taking firms. However, the gift shop in a museum or zoo does not differ technologically from a profit-taking retail outlet selling similar goods. All of these examples are consistent with the present modelling of an organization that operates a net-revenue generating technology, $R=f(e)$.

Further, charities use net donation revenues to provide free food and shelter to the indigent, or to fund counselling programs, as well as to compensate their employees. A nonprofit hospital uses some of it's fee-for-service

\footnotetext{
${ }^{10}$ The present analysis would not apply to a charity that hires a professional (and profitmaximizing) fund-raiser. as many do. Slivinski and Steinberg(1997) analyzes the external/internal fund-raising decision of charitable organizations, while other recent papers by Andreoni(1998) and Vesterlund(1998) analyze other aspects of charitable fund-raising.
} 
revenue to provide free medical care to those without the means to pay for it, or to fund medical research. Local youth hockey associations use some of the revenues earned from membership fees, bingo, and skate-a-thons to buy trophies and ice time for the adolescents who sign up for league play. The net revenues from the museum or zoo gift shop can be used to acquire more art or animals for the collection or to maintain the existing collections. Indeed, involvement in some public service activity is typically referred to as a nonprofit organization's 'primary mission', ${ }^{11}$ and is generally necessary for obtaining legal nonprofit status.

Holmstrom showed that in a team with (8) holding, and utilities quasilinear in $x_{i}$, no credible allocation scheme could be devised that would provide incentives for efficient effort choices within a P-team. His result is a special case of Proposition 1.

Proposition 1 Suppose $a^{*}=\left(x^{*}, e^{*}, y^{*}\right)$ is an interior efficient allocation for a team, that $\Gamma=(\sigma, \theta)$ is credible, satisfies (5), and

$$
\Gamma\left(f\left(e^{*}\right)\right)=\left(\sigma\left(f\left(e^{*}\right)\right), \theta\left(f\left(e^{*}\right)\right)\right)=\left(x^{*}, y^{*}\right) .
$$

Then $e^{*}$ cannot be a Nash equilibrium of the game induced by $\Gamma$.

The proof of this Proposition under the assumption that $\Gamma$ is differentiable at $f\left(e^{*}\right)$ and $y^{*}>0$ is simple and does not use the requirement that $\Gamma$ be credible, other than (6). It is given below, while the rather longer proof of the actual Proposition, is in the Appendix.

Proof: If $a^{*}$ is an interior efficient allocation, suppose $e^{*}$ is also a Nash equilibrium in a game induced by the compensation scheme, $\Gamma=(\sigma(), \theta())$. If $\Gamma$ is differentiable at $f\left(e^{*}\right)$, then it must be that:

$$
\frac{\partial \mu_{i}\left(e^{*}\right)}{\partial e_{i}}=\left[u_{i}^{\prime}\left(\sigma_{i}\left(f\left(e^{*}\right)\right)\right) \sigma_{i}^{\prime}\left(f\left(e^{*}\right)\right)+m_{i}^{\prime}\left(\theta\left[f\left(e^{*}\right)\right]\right) \theta^{\prime}\left(f\left(e^{*}\right)\right)\right] f_{i}\left(e^{*}\right)-v_{i}^{\prime}\left(e_{i}^{*}\right)=0
$$

for all $i=1, \ldots, n$.

\footnotetext{
${ }^{11}$ There are some nonprofit organizations that do not seem to fit this formulation, in that they do only one thing. For example, nonprofit daycare centers do nothing but provide day care. That is their mission as well as their means of generating net revenue. Another way to model the 'taste difference' that characterizes nonprofit organizations is to assume nonprofit managers have a preference for higher output. Lakdawalla and Philipson(1998) employ such a model, which does encompass the daycare industry.
} 
yields:

Dividing both sides of each of these expressions by $u_{i}^{\prime}\left(\sigma_{i}\left(f\left(e^{*}\right)\right)\right) f_{i}\left(e^{*}\right)>0$

$$
\sigma_{i}^{\prime}\left(f\left(e^{*}\right)\right)+\frac{m_{i}^{\prime}\left(\theta\left[f\left(e^{*}\right)\right]\right)}{u_{i}^{\prime}\left(\sigma_{i}\left(f\left(e^{*}\right)\right)\right)} \theta^{\prime}\left(f\left(e^{*}\right)\right)=\frac{v_{i}^{\prime}\left(e_{i}^{*}\right)}{u_{i}^{\prime}\left(\sigma_{i}\left(f\left(e^{*}\right)\right)\right) f_{i}\left(e^{*}\right)}=1, \text { for all } i .
$$

The last equality follows because $a^{*}$ is efficient, and so satisfies (1). If we then sum these expressions over $i$ we get that it must be true that:

$$
\sum_{i=1}^{n} \sigma_{i}^{\prime}\left(f\left(e^{*}\right)\right)+\theta^{\prime}\left(f\left(e^{*}\right)\right) \sum_{i=1}^{n} \frac{m_{i}^{\prime}\left(\theta\left[f\left(e^{*}\right)\right]\right)}{u_{i}^{\prime}\left(\sigma_{i}\left(f\left(e^{*}\right)\right)\right)}=n
$$

However, if $a^{*}$ is efficient and $\Gamma()$ is budget-balanced, (2) and (6) imply that the left hand side of this expression equals 1 , which is a contradiction if there are at least two team members.

This result is true whether or not (8) holds, hence it implies that the team incentive problem represents a similar obstacle to both types of firms. What turns out to be different are the means they have available to solve it.

In what follows, a team for which (8) holds will be referred to as a P-team, otherwise, it will be termed a NP-team.

\section{$2.1 \quad$ P-team implications}

Proposition 1 can be viewed as simply one example of a well-known fact; Nash equilibria are generically inefficient. What is interesting, for present purposes, however, is Holmstrom's further demonstration that a particular modification of the structure of a P-team implies that there exist many credible compensation schemes which do induce efficient effort choices. The modification is to add another member to the team who differs in one key respect; he provides no unobservable inputs. Alternatively, assume that for this new 'agent 0 ' it is true that $f_{0}(e) \equiv 0$, so that in any efficient allocation, $e_{0}^{*}=0$. I adopt the neutral term principal for a team member in this position, whereas team members for whom $f_{i}>0$ are referred to as agents. A team which includes no principal will be referred to as an 'all-agent team', following the terminology used in Andolfatto and Nosal (1998).

One compensation scheme that induces efficient effort once the principal is introduced takes the form: 


$$
\sigma_{i}^{f}(R)=\left\{\begin{array}{l}
x_{i}^{*}, \text { if } R \geq R^{*} \\
a_{i}, \text { if } R<R^{*}
\end{array} \text { for } i=1, \ldots, n\right.
$$

where $\left(e^{*}, x^{*}\right.$ ) is efficient (so $\left.e_{0}^{*}=0\right), R^{*}=f\left(e^{*}\right)$, and each $a_{i}<x_{i}^{*}$ is set so that $u_{i}\left(a_{i}\right)-v_{i}(0) \leq u_{i}\left(x_{i}^{*}\right)-v_{i}\left(e_{i}^{*}\right)$.

Then, $\sigma_{0}()$ is simply;

$$
\sigma_{0}^{f}(R) \equiv R-\sum_{i=1}^{n} \sigma_{i}(R)
$$

This is simply the team version of a forcing contract. For this contract to provide incentives to choose $e^{*}$, it is necessary that the principal not supply any unobservable inputs. With his compensation determined by $\sigma^{f}()$, it will always be in his interest to choose $e_{0}=0$ if $f_{0}\left(e^{*}\right)>0 .{ }^{12}$ The principal may, however, perform any number of other tasks within the firm, such as providing financial capital, and choosing the technology and other inputs used to generate $R$. He may even be the one who designs the compensation scheme itself. If that is the case, then it is in his interest to design an incentive scheme which motivates the other team members to provide the efficient effort vector that forms part of the solution to the problem:

$$
\begin{aligned}
& \max _{x, e} x_{0}=f(e)-\sum_{i=1}^{n} x_{i}, \text { subject to: } \\
& u_{i}\left(x_{i}\right)-v_{i}\left(e_{i}\right) \geq \bar{U}_{i}, \text { for } i=1, \ldots, n .
\end{aligned}
$$

This allocation thus maximizes the team's profit, which, since $e_{0} \equiv 0$, is also the principal's payoff. The values $\overline{U_{i}}$ can be interpreted as the payoffs necessary to keep the agents willing to stay in the team. The $\sigma_{i}()$ in (10) can be interpreted as giving individuals a base salary of $a_{i}$, with a bonus of $x_{i}^{*}-a_{i}$ if the organization reaches the target level of performance, $R^{*}$. However, many other compensation schemes can also be used to induce an efficient outcome once a principal is introduced.

It is difficult to view the principal as either a corporate $\mathrm{CEO}$ or a single entrepreneur in business for himself, in view of the critical requirement that he provide no unobservable inputs to the team. Rather, the principal must be

\footnotetext{
${ }^{12}$ That is, 0 's best-response to $e_{-0}^{*}$ is $e_{0}=0$. If the game induced by using (11) and (10), with $R^{*}=f\left(e_{0}^{*}, e_{-0}^{*}\right)$ has any Nash equilibriium when $f_{0}^{\prime}>0$, it must be $e^{n}=0$.
} 
either a stockholder or silent partner who plays no direct role in the operation of the firm.

Note that the concept of efficiency used here refers only to allocations within the team. That is, an efficient $\left(e^{*}, x^{*}\right)$ is one such that no other allocation can yield higher payoffs to anyone within the team without also resulting in lower payoffs to other team members. A firm that attains an efficient allocation may, for example, be a monopoly that is producing an inefficiently low quantity of some commodity in attaining that allocation. Throughout the rest of the paper, the concepts of efficiency and second-best that are employed should be understood in this sense.

\section{$2.2 \quad$ Np-Team implications}

Does the introduction of a principal play a similar role in permitting a NPteam to deal with the team incentive problem? Specifically, does it allow for the construction of a $\Gamma$ that induces an efficient outcome. The answer is yes.

Suppose then that $m_{i}^{\prime}>0$ for at least some $i \in\{0,1, \ldots, n\}$, that $f_{0} \equiv 0$, and that $a^{*}$ is an efficient allocation. Let $R^{*}=f\left(e^{*}\right)$, and consider the following allocation scheme:

$\Gamma^{+}(R)=\operatorname{argmax}_{(x, y)}\left\{\begin{array}{c}u_{0}\left(x_{0}\right)+m_{0}(y) \mid u_{i}\left(x_{i}\right)+m_{i}(y) \geq \tau_{i}(R), \forall i \neq 0, \text { and } \\ \sum_{i=0}^{n} x_{i}+y \leq R\end{array}\right\}$,

where

$$
\tau_{i}(R)=\left\{\begin{array}{c}
u_{i}\left(x_{i}^{*}\right)+m_{i}\left(y^{*}\right), \text { if } R \geq R^{*} \\
u_{i}\left(x_{i}^{*}\right)+m_{i}\left(y^{*}\right)-\varepsilon_{i}, \text { if } R<R^{*}
\end{array}\right.
$$

and

$$
\varepsilon_{i} \geq v_{i}\left(e_{i}^{*}\right)-v_{i}(0) .
$$

That this will induce each $i$ other than 0 to choose $e_{i}^{*}$ follows from the observations:

$$
\begin{aligned}
& \mu_{i}\left(e_{i}, e_{-i}^{*}\right)=u_{i}\left(x_{i}^{*}\right)+m_{i}\left(y^{*}\right)-v_{i}\left(e_{i}\right)<W_{i}\left(a_{i}^{*}\right)=\mu_{i}\left(e^{*}\right), \text { if } e_{i}>e_{i}^{*}, \text { and } \\
& \mu_{i}\left(e_{i}, e_{-i}^{*}\right)=u_{i}\left(x_{i}^{*}\right)+m_{i}\left(y^{*}\right)-\left(\varepsilon_{i}+v_{i}\left(e_{i}\right)\right) \leq W_{i}\left(a_{i}^{*}\right), \text { if } e_{i}<e_{i}^{*} .
\end{aligned}
$$

Furthermore, $\Gamma^{+}$is credible by construction. Note that for any $R$ and for any $i \neq 0$, it will be true that $u_{i}\left(\sigma_{i}^{+}(R)\right)+m_{i}\left(\theta^{+}(R)\right)=\tau_{i}(R)$, otherwise $x_{i}$ could be reduced and $x_{0}$ increased. Similarly, it will always be true that $\sum \sigma_{i}^{+}(R)+\theta^{+}(R)=R$, otherwise $x_{0}$ could be increased to the benefit of the principal. $\sigma_{i}^{+}()$is analogous to $\sigma_{i}^{f}()$ for $i \neq 0$, except that the $x_{i}$ a shirking 
agent receives will in general vary with his choice of $e_{i}$, since $R$ will, as will then $y=\theta^{+}(R)$. Finally, if for some $i, m_{i}^{\prime} \equiv 0$, then $\sigma_{i}^{+}$is identical to $\sigma_{i}^{f}$, in that it implies that any $R<R^{*}$ results in $\sigma_{i}(R)=a_{i}$ where $a_{i}$ is defined by $u_{i}\left(a_{i}\right)=u_{i}\left(x_{i}^{*}\right)-\varepsilon_{i}$.

If the team allocation scheme is chosen to maximize the principal's payoff, it will implement the particular efficient outcome:

$$
a^{\circ}=\operatorname{argmax}_{a}\left\{\begin{array}{c}
u_{0}\left(x_{0}\right)+m_{0}(y) \mid W_{i}\left(a_{i}\right) \geq \omega_{i}, \text { for } i=1, \ldots, n ; \text { and } \\
\sum_{i=0}^{n} x_{i}+y \leq f(e)
\end{array}\right\}
$$

where each $\omega_{i}$ is the payoff team member $i$ can earn outside the team. Inducing this outcome simply requires setting $R^{*}=f\left(e^{\circ}\right)$ in (14) Further, if the principal doesn't care about $z$, so that $m_{0}^{\prime} \equiv 0$, then the allocation $a^{0}$ will be that which maximizes $x_{0}=f(e)-y-\Sigma_{i>0} x_{i}$, which can be considered 'profit'. However, the allocation $a^{\circ}$ may still have $y^{\circ}>0$, if any other members of the team care about $y$, since putting some net revenues into $z$ production may then represent an efficient means of compensating the agents. If (8) holds, $a^{\circ}$ is precisely the profit-maximizing allocation, (with $y^{\circ}=0$ ), and $\Gamma^{+}$is identical to $\Gamma^{f}$, above. When (8) does not hold, however it is notable that the organization can still be viewed as a standard profittaking firm, which provides certain local public goods to it's employees as part of their compensation. Such things as lunch-room or exercise facilities, access to corporate boxes for sporting events, or even a company paid health or dental care plan can all be modelled as part of $z$. In this context, Prop. 1 can be read as implying that making the level of expenditure on such 'organizational public goods' a function of team outcomes is not a means for an all-agent profit-taking firm to evade the team incentive problem.

As with a P-team, the fact that $\Gamma^{+}$induces an efficient outcome for an NP-team relies crucially on the fact that $f_{0} \equiv 0$, since otherwise the principal would have an incentive to shirk herself and trigger the 'punishment' phase of $\Gamma^{+}$, just as in a P-team. The question now becomes whether there are individuals who play the role of principal in actual nonprofit organizations.

In a P-team, the principal can be interpreted as a stockholder in the organization (as represented by the Board of Directors, perhaps). It is not obvious who in a nonprofit organization can play this role, since such organizations cannot have stockholders. The 'non-profit entrepreneurs' who found and operate nonprofit organizations provide effort that is important to the organization's generation of net revenues, so the requirement that $f_{0} \equiv 0$ is simply not met. The same is true for any of the upper management of 
non-profit organizations, so none of these P-team members can serve as the required Principal. Two alternative possibilities suggest themselves, however.

Considering that the principal is an agent who gets utility from receiving some portion of net revenues, as well as from the provision of $z$, it is possible to interpret her as 'the government'. In this interpretation, $x_{0}$ is simply the tax revenue that the government earns as a function of the net revenues generated by the NP-team, and $m_{0}()$ reflects the extent to which the government 'cares' about the NP-team's primary mission. Thus, $W_{0}\left(x_{0}, y\right)=u_{0}\left(x_{0}\right)+m_{0}(y)$ can be seen as representing the government's payoff from the activities of the organization. A benign interpretation of the government's role would have $m_{0}$ encapsulating the 'value to society' of the organization's primary mission, although such an interpretation is not necessary. One can also simply think of $W_{0}$ as capturing the derived motivations of a regulatory body given the task of monitoring the operation of nonprofit organizations in some particular jurisdiction. However one views $W_{0}$, it is also not difficult to specify the $u_{0}$ function in such a way that the efficient outcome implemented has $x_{0}<0$, which can then be interpreted as a government grant. Note that there is no reason to expect that the particular efficient outcome $a^{\circ}$ defined in (16) is implemented under this interpretation of the principal as government, as it is not clear that a government agency has the means to impose an incentive scheme that induces $a^{\circ}$. On the other hand, if team member 1 is interpreted as the founder, or CEO of the organization, we might expect the internal allocation induced to be one that maximizes $W_{1}$, subject to $W_{j} \geq \omega_{j}$ for $j \neq 1$. Then $\omega_{0}$ can be interpreted as the minimum payoff to the government agency necessary to keep it from interfering with the organization's operation, or perhaps revoking it's nonprofit status. A suitably altered version of the allocation scheme $\Gamma^{+}$defined above, among many others, can be used to implement that efficient allocation.

A second, more inventive interpretation of the NP-principal is that she is a donor, with $m_{0}$ being the payoff to the donor from the organization's primary mission. Again, $u_{0}$ can easily be specified in a way that implies that in an efficient allocation, $x_{0}<0$, so that it is in fact efficient for the principal to make a donation. Since donors are not typically in a position to influence the internal operation of the organization, the allocation implemented may be one that maximizes $W_{i}$ for some $i \neq 0$, in this interpretation of the principal's identity.

However, the most compelling interpretation of the role of the principal would seem to be the following. In addition to the fact that $f_{0} \equiv 0$, suppose 
that the allocation mechanism for the NP-team is constrained to satisfy:

$$
\sigma_{0}(R) \equiv x_{0},
$$

so the principal's private compensation is required to be constant. Nonprofit organizations face various regulatory constraints, and one that is often imposed as a condition of being granted nonprofit status is a requirement that upper management not receive 'excessive compensation'. The constraint (17) cannot be interpreted as a legal and binding upper bound on the compensation paid to a nonprofit organization's CEO, however, since such an individual's role in the firm is not going to be one for which $f_{0} \equiv 0$ is a reasonable characterization.

On the other hand, virtually every nonprofit organization is overseen by a Board of Trustees or Directors that leaves the daily operation of the organization in the hands of it's upper management, providing only broad oversight and direction. ${ }^{13}$ Members of the Board are not permitted to be residual claimants, and normally receive only some token, fixed compensation for their services. ${ }^{14}$ An individual for whom $f_{0} \equiv 0$ holds, and who receives only some nominal fixed payment for playing this role, can be interpreted as such a Trustee.

Further, if Trustees do care about the provision of $z$, viewing this as indeed the 'primary mission' of the organization, then the most-preferred allocation from their perspective will be the one that solves the problem:

$$
\begin{gathered}
\max _{a} y=f(e)-\bar{x}_{0}-\sum_{i=1}^{n} x_{i} \\
\text { subject to: } \\
W_{i}\left(a_{i}\right) \geq \omega_{i}, \text { for } i=1, \ldots, n .
\end{gathered}
$$

In what follows, let $a^{b}=\left(x^{b}, e^{b}, y^{b}\right)$ be the solution to this problem. Necessary conditions for $a^{b}$ to be a solution to this are:

$$
u_{i}^{\prime}\left(x_{i}^{b}\right) f_{i}\left(e^{b}\right)=v_{i}^{\prime}\left(e_{i}^{b}\right) \text { for } i=1, \ldots, n
$$

\footnotetext{
${ }^{13}$ Handy (1995) argues that board members may also lend their collective 'prestige' to the organization as a bond to engender public trust in the organization.

${ }^{14} \mathrm{~A}$ recent survey of over 700 nonprofit organizations by Independent Sector found that all but $1 \%$ of them paid Board members nothing more than reimbursement of expenses connected with attending Board meetings.
} 
and

$$
\sum_{i=1}^{n} \frac{m_{i}^{\prime}\left(y^{b}\right)}{u_{i}^{\prime}\left(x_{i}^{b}\right)}=\rho^{b}<1
$$

as well as: $y^{b}+\bar{x}_{0}+\sum_{i=1}^{n} x_{i}^{b}=f\left(e^{b}\right)$.

It is immediate that the allocation scheme $\Gamma^{b}$ will implement this allocation, where:

$$
\Gamma^{b}(R)=\arg \max _{a}\left\{y \mid u_{i}\left(x_{i}\right)+m_{i}(y) \geq \tau_{i}^{b}(R), \text { for } i \geq 1, \bar{x}_{0}+\sum_{i=1}^{n} x_{i}+y \leq R\right\}
$$

and where

$$
\tau_{i}^{b}(R)=\left\{\begin{array}{c}
u_{i}\left(x_{i}^{b}\right)+m_{i}\left(y^{b}\right), \text { if } R \geq R^{b} \equiv f\left(e^{b}\right) \\
u_{i}\left(x_{i}^{b}\right)+m_{i}\left(y^{b}\right)-\varepsilon_{i}, \text { if } R<R^{b}
\end{array} .\right.
$$

One way to characterize $\Gamma^{b}$ is that it defines the role of the Trustee as principal in such a way that the production of $z$ effectively becomes the residual claimant on the net revenues of the NP-team.

While the introduction of a principal/Trustee does allow for a solution to the NP-team incentive problem, there is a problem with this solution at another level. If the Board of Directors of a publicly held profit-making corporation does not effectively generate profits from a $P$-team, an ultimate form of discipline is imposed on it by the market for corporate control. Because the rights to the profits of the P-team are 'alienable', anyone who believes that greater profits can be extracted from it can purchase sufficient shares to allow them to replace the management, change the compensation scheme or technology, to do whatever is required to increase profits. It's not clear how individuals who believe some nonprofit organization could generate greater $y$ might acquire control of the organization, since Boards of Trustees of nonprofit organizations are most often self-perpetuating bodies. Any take over of a nonprofit organization is a political act, since even joining the Board requires the consent of a majority of existing members. The 'market' for this sort of organizational control clearly operates very differently from that for corporate control. ${ }^{15}$.

The analysis above does justify, in a sense, the restrictions on organizational structure imposed by nonprofit incorporation statutes. Nonprofits are

\footnotetext{
${ }^{15}$ Brody (1996) contains a detailed discussion of the role of Nonprofit Boards, including a comparison of their workings to that of the Boards of for-profit firms.
} 
typically said to be subject to a 'nondistribution constraint', which Hansmann has characterized as a prohibition on '...distributing residual earnings to individuals who exercise control over the firm, such as officers, directors, or members' (Hansmann, (1987)). In the model developed here, if the Boards of nonprofit organizations do effectively play the role of principal, this implies that the outcome for a NP-team will be the one that solves (18). The allocation $a^{b}$ is that which maximizes the level of $y$, subject to keeping all agents as team members, and the Trustee/principal's presence on the team implies that $a^{b}$ can be attained. If encouraging the pursuit of nonprofit organizations' primary missions was the reason that organizational form was codified into law, this suggests that it has the desired effect.

\section{The Implications of Regulation}

Nonprofit organizations are regulated in a variety of ways that go beyond the imposition of a non-distribution constraint. Such regulation is generally designed to encourage organizations to pursue their 'primary mission', captured here as the production of $z$ through the diversion of net revenues into $y$. However, any regulations of this type can also have implications for the ability of the organization to induce efficient effort from its members, for two related reasons. First such regulation will typically change the set of feasible team allocations. That implies that a regulated NP-team may be trying to implement a second-best allocation. Second, the set of allocation mechanisms available to the team may be restricted by the imposition of such regulations.

The fact that the team can at best implement a constrained-efficient allocation, and must do so using a reduced space of allocation mechanisms, could mean that the introduction of a principal is no longer necessary. That is, it may be that a second-best team allocation can be induced even though all team members are contributing unobservable effort. The proof of Proposition 1 above relies crucially on the fact that it is an efficient allocation that is being implemented, so it could be that implementation of second-best allocations in an all-agent NP-team is possible, rendering the results above irrelevant for regulated nonprofit organizations. In this section this possibility is investigated for two types of regulation that are commonly imposed on non-profit organizations.

Current practice in regulating nonprofits allows the upper management to 
have many types of incentive and bonus clauses in their contracts. However, nonprofit statutes generally enjoin those who operate, found or manage such organizations from being awarded 'excessive compensation'. Just what constitutes an 'excessive' level of compensation is not clear, but the important point is that it is not the form of compensation to a nonprofit entrepreneur or manager that is regulated, but rather the level.

Consider then an all-agent team, in which at least some members care positively about $y$. I will let agent 1 be the team member to whom the compensation regulation applies, and refer to him as the entrepreneur in what follows. In the absence of any regulation, the entrepreneur would wish to see the allocation $a^{*}$ implemented, where $a^{*}$ is the solution to:

$$
\begin{aligned}
& \max _{a} W_{1}\left(a_{1}\right) \\
& \text { subject to } W_{j}\left(a_{j}\right) \geq \omega_{j} \text { for } j=2, \ldots . n \text { and } \\
& y+\sum_{i=1}^{n} x_{j} \leq f(e)
\end{aligned}
$$

A prohibition against excessive compensation would require that any allocation mechanism used by the team satisfy:

$$
\sigma_{1}(R) \leq \bar{x}_{1}, \text { for all } R \text {. }
$$

If this is an effective constraint, meaning that $x_{1}^{*}>\bar{x}_{1}$, it follows that the second-best allocation the entrepreneur would want to implement, denoted here as $a^{1}$, will necessarily satisfy:

$$
\begin{aligned}
x_{1}^{1} & =\bar{x}_{1}, \\
f_{1}\left(e^{1}\right)\left(u_{1}^{\prime}\left(x_{1}^{1}\right)+\delta\right) & =v_{1}^{\prime}\left(e_{1}^{1}\right), \text { for } \delta \leq 0, \\
f_{i}\left(e^{1}\right) u_{i}^{\prime}\left(x_{i}^{1}\right) & =v_{i}^{\prime}\left(e_{i}^{1}\right), \text { for } i=2, \ldots, n .
\end{aligned}
$$

and

$$
\frac{m_{1}^{\prime}\left(y^{1}\right)}{u_{1}^{\prime}\left(x_{1}^{1}\right)+\delta}+\sum_{i=2}^{n} \frac{m_{i}^{\prime}\left(y^{1}\right)}{u_{i}^{\prime}\left(x_{i}^{1}\right)}=1,
$$

A second type of regulation is directly targeted at the goal of inducing greater $y$ from the organization, as it imposes the added constraint;

$$
\theta(R) \geq \bar{y}, \text { for all } R
$$


on the allocation scheme used by the NP-team. The rationale for such a regulation is transparent, given that individuals outside the organization presumably care about the $z$ that $y$ finances. It can be seen as a way of forcing the nonprofit organization to consider the interests of those outside the organization. ${ }^{16}$ Assuming again that this constraint is effective, in that $y^{*}<\bar{y}$, it follows that the second-best allocation the entrepreneur wants to implement, $a^{r}$, will satisfy:

$$
\begin{aligned}
y^{r} & =\bar{y} \\
f_{i}\left(e^{r}\right) u_{i}^{\prime}\left(x_{i}^{r}\right) & =v_{i}^{\prime}\left(e_{i}^{r}\right), \text { for all } i, \text { and } \\
\sum_{i=1}^{n} \frac{m_{i}^{\prime}\left(y^{r}\right)}{u_{i}^{\prime}\left(x_{i}^{r}\right)} & =\beta<1
\end{aligned}
$$

We are interested in whether such second-best allocations can be attained using allocation schemes that do not feature a principal. Note that the credibility of any allocation scheme must take into account any relevant regulatory constraints, also. That is, $\Gamma$ must be ex-post constrained efficient: for each $R$, there must be no ex-post allocation $(x, y)$ satisfying either $x_{1} \leq \bar{x}$ or $y \geq \bar{y}$, respectively, that dominates $\Gamma(R)$. This is consistent with our general assumption that there is no possibility of 'secret' ex-post renegotiations. The next result shows that the team incentive problem exists for a regulated NP-team, also.

Proposition 2 (i) Let $a^{1}$ be an interior solution to (20) with the added constraint $x_{1} \leq \bar{x}_{1}$. Then there is no credible allocation scheme $\Gamma=(\sigma, \theta)$ satisfying (21) such that the Nash equilibrium of the game induced by $\Gamma$ results in the allocation $a^{1}$.

(ii) Let $a^{r}$ be an interior solution to (20) with the added constraint $y \geq \bar{y}$. Then there is no credible allocation scheme $\Gamma$ satisfying (26) such that the Nash equilibrium of the game induced by $\Gamma$ results in $a^{r}$.

Proof: See the appendix.

Proposition 2 implies that an all-agent nonprofit organization that is subject to either of these two types of regulations cannot solve the second-best

\footnotetext{
${ }^{16}$ It was once common to require of nonprofit hospitals that they provide a minimum amount of 'uncompensated care' in order to maintain their nonprofit status, although such requirements have become rare, more recently. In a similar vein, charities are sometimes required to devote a minimum percentage of their collected donations to their primary mission, rather than to employee compensation or other costs of doing business.
} 
team-incentive problem, either. It is not hard to devise a credible $\Gamma$ that will induce either of the second-best allocations once a principal is introduced into the team.

\section{Predictions and Extensions}

The results above suggest that the nonprofit form carries with it no inherent disadvantage in solving the team incentive problem. Just as in a profitmaking organization, the problem cannot be solved using an all-agents contract. However, again just as in a profit-making firm, the introduction of a principal that supplies no unobservable inputs does permit the team problem to be solved. Of course, organizations must deal with many other incentive issues, and it may be that nonprofit organizations differ from profit-taking firms in their ability to deal with any number of them. In short, a lot of work remains to be done in seeking theoretical predictions on differences in for-profit/nonprofit behavior. The analysis above already implies that the two types of organizations will implement different outcomes, ceteris paribus. This in itself can generate predictions regarding differences in observed behavior.

To see this, consider the special case in which team members' preferences are quasi-linear in $x_{i}$, so that $u_{i}\left(x_{i}\right)=x_{i}$. Then it is immediate that any credible $\Gamma$ has $\theta(R)=\min \left\{R, y^{*}\right\}$, where $y^{*}$ is uniquely characterized by $\Sigma_{i} m_{i}^{\prime}\left(y^{*}\right)=1$. Consider a P-team that produces no $y$, and includes a princi$\mathrm{pal}$, and which is therefore going to implement the allocation that maximizes $x_{0}$, subject to all $U_{i}\left(a_{i}\right) \geq \omega_{i}$. Compare this to a NP-team with the same $f()$, and a set of agents who are identical to those in the NP-team, except that at least some get utility from $y$. If this firm includes a principal/trustee, it will seek to implement the $a$ that maximizes $y$, subject to $W_{i}\left(a_{i}\right) \geq \omega_{i}$ for all $i \neq 0$. It is immediate that the $e$ vectors that are efficient for each team are identical in these two organizations, hence so are the two sets of $R$ values that might arise. However, the $y$ production of the NP-team implies that any NP-team members who also care about $y$ will receive lower compensation than they would in the P-team, since an efficient allocation in either team will hold them to the same $\omega_{i}$, but in the NP-team that utility will be achieved partly due to the provision of $y$. This provides a theoretical justification for including a dummy variable for 'organizational structure' in a regression which tries to explain employee compensation levels in a set of 
organizations of both types.

It was noted above that a P-team principal who does not care about $z$, may still find it in his interest to implement an efficient allocation in which $y>0$, if some agents care about $z$. However, the absence of a restriction on $x_{0}$ in the P-team will result in it producing less $y$ than in an otherwise identical NP-team directed by a principal/trustee for whom $\sigma_{0}(R) \equiv \bar{x}_{0}$. This observation provides the basis for a simple model of entrepreneurial selection. Entrepreneurs who care more about $y$ will tend to found nonprofit organizations, whether or not the employees care about $y$, also. Of course NP-teams will often have a different $f()$ than a P-team simply as a result of the latter's treatment by the tax system. Incorporating these tax features explicitly into a model of the entrepreneur's choice of organizational form is likely to prove useful.

There are ways other than the introduction of principals to induce efficient effort in a team situation. Members of any organization are engaged in a repeated game, so the compensation they get can be made to depend on the history of the team outcomes. It is well known that in infinitely repeated games there generally exist strategies that allow the players to attain nearly efficient payoffs, if the future matters enough. While it may be reasonable to view organizations as infinitely lived, agents belong to a team for only a finite span of time. Cremer (1986) considered the possibility of enforcing efficient outcomes when agents can be thought of 'overlapping cohorts', each of which are in the organization for a finite number of periods. It is shown there that the best that can be done in such an environment is the attainment of approximately efficient effort profiles, implying that introducing a principal into the team may still be a superior solution.

Some work on the standard team problem assumed that effort is a stochastic function of output, rather than a deterministic one (see Dutta and Radner(1993), d'Aspremont and Gerard-Varet(1998)) An attempt to generate $\mathrm{P} / \mathrm{NP}$ differences in a model of stochastic team production is worth pursuing and Slivinski (1999) contains some preliminary results on this issue.

\section{Appendix}

It will be useful to have some notation and definitions available for what follows. 
Notation: If $x$ is an n-vector, then $x \geqq x^{\prime}$ implies $x_{i} \geq x_{i}^{\prime}$ for all $i$, while $x \geq x^{\prime}$ means $x \geqq x^{\prime}$ and not $x^{\prime} \geqq x$.

Let $A(R)=\left\{(x, y) \mid \Sigma_{i} x_{i}+y \leq R\right.$, and $\left.(x, y) \geqq(\underline{x}, 0)\right\}$. Then, for each $i$, let $V_{i}\left(x_{i}, y\right)=u_{i}\left(x_{i}\right)+m_{i}(y)$, and define

$$
V(x, y)=\left(V_{1}\left(x_{1}, y\right), \ldots, V_{n}\left(x_{n}, y\right)\right) .
$$

We can define the set of efficient ex-post allocations, given any realized $R$, as:

$$
O(R)=\left\{(x, y) \in A(R) \mid V\left(x^{\prime}, y^{\prime}\right) \geq V(x, y) \Rightarrow\left(x^{\prime}, y^{\prime}\right) \notin A(R)\right\} .
$$

Now, a preliminary result.

Lemma 1: $O()$ is a closed correspondence from the non-negative reals into $\{(x, y) \mid(x, y) \geq(\underline{x}, 0)\}$.

Proof: . Suppose, by way of contradiction, that $O()$ is not closed. Then there exists a sequence $\left(x^{k}, y^{k}, R^{k}\right) \rightarrow\left(x^{o}, y^{o}, R^{o}\right)$ such that $\left(x^{k}, y^{k}\right) \in O\left(R^{k}\right)$ for all $k$, but $\left(x^{\circ}, y^{\circ}\right) \notin O\left(R^{\circ}\right)$. Since addition is continuous, it follows that $\Sigma x_{i}^{o}+y^{\circ}=R^{\circ}$, hence $\left(x^{o}, y^{\circ}\right) \in A\left(R^{\circ}\right)$. This then implies there is some $\left(x^{\prime}, y^{\prime}\right) \in A\left(R^{o}\right)$ such that $V\left(x^{\prime}, y^{\prime}\right) \geq V\left(x^{o}, y^{o}\right)$. Let $(x(\lambda), y(\lambda))=\lambda\left(x^{\prime}, y^{\prime}\right)+$ $(1-\lambda)\left(x^{\circ}, y^{\circ}\right)$, so that for all $\left.\lambda \in\right] 0,1[$, and for all $i$, we have either;

$$
\begin{gathered}
V_{i}\left(x_{i}(\lambda), y(\lambda)\right)>V_{i}\left(x_{i}^{o}, y^{o}\right), \text { or } \\
V_{i}\left(x_{i}(\lambda), y(\lambda)\right)=V_{i}\left(x_{i}^{o}, y^{o}\right), \text { and } x_{i}^{\prime}=x_{i}^{o}
\end{gathered}
$$

since $V_{i}$ is strictly increasing in $x_{i}$. The second group cannot comprise all individuals, since if it did we must have $y^{\prime}>y^{\circ}$ in order to have some individuals strictly prefer $\left(x_{i}^{\prime}, y^{\prime}\right)$ to $\left(x_{i}^{o}, y^{\circ}\right)$, and this would imply that $\Sigma x_{i}^{\prime}+$ $y^{\prime}>\Sigma x_{i}^{o}+y^{o}=R^{o}$. For those for whom the strict inequality holds, if $x_{i}(\lambda)=\underline{x}_{i}$, then it must be that $y(\lambda)>y^{\circ}$. If this is true for all $i$ in this group, then since it is true for all in the second group, it would follow that $R^{\circ}=\Sigma_{i} x_{i}(\lambda)+y(\lambda)>\Sigma_{i} x_{i}^{o}+y^{o}$, a contradiction. So there must be at least one $i$ in the first group for whom $x_{i}(\lambda)>\underline{x}_{i}$. Let $n^{\prime} \geq 1$ be the number of such individuals, and let $N^{\prime}$ denote the set of them.

The continuity of the $V_{i}$ implies the existence of a $\varepsilon>0$ such that for all $i$ in $N^{\prime}, V_{i}\left(x_{i}(\lambda)-\varepsilon, y(\lambda)\right)>V_{i}\left(x_{i}^{o}, y^{\circ}\right)$. Now, define an allocation $\left(x^{a}, y^{a}\right)$ as $y^{a}=y(\lambda)+\frac{\varepsilon}{4}, x_{i}^{a}=x_{i}(\lambda)-\varepsilon$, if $i$ is in $N^{\prime}$, and $x_{i}^{a}=x_{i}(\lambda)+\frac{\left(n^{\prime}-1 / 2\right) \varepsilon}{2\left(n-n^{\prime}\right)}$ if $i$ is not in 
$N^{\prime}$. Then it follows that $V\left(x^{a}, y^{a}\right)>V\left(x^{\circ}, y^{\circ}\right)$ and that $\Sigma x^{a}+y^{a}=R^{\circ}-\frac{e n^{\prime}}{2}$. But then, since $\left(x^{k}, y^{k}, R^{k}\right) \rightarrow\left(x^{\circ}, y^{o}, R^{\circ}\right)$ and the $V_{i}$ are all continuous, there must exist a $k^{\prime}$ such that for all $k>k^{\prime}$, we have $V\left(x^{a}, y^{a}\right)>V\left(x^{k}, y^{k}\right)$ and $\Sigma x^{k}+y^{k}=R^{k}>R^{o}-\frac{s n^{\prime}}{2}$ which contradicts the hypothesis that $\left(x^{k}, y^{k}\right) \in$ $O\left(R^{k}\right)$ for all $k$.

Proof of Proposition 1: Suppose that $a^{*}=\left(x^{*}, e^{*}, y^{*}\right)$ is efficient, and that $R^{*}=f\left(e^{*}\right)$, and suppose by way of contradiction that $\Gamma=\langle\sigma, \theta\rangle$ satisfies (5) and is credible. Let $F_{i}\left(e_{i}\right) \equiv f\left(e_{i}, e_{-i}^{*}\right), h_{i}(R)=F_{i}^{-1}(R)$, let

$$
\mathcal{R}_{i}=\left\{R \mid F_{i}\left(e_{i}\right)=R, \text { for some } e_{i}\right\}=F_{i}([0,1])
$$

and $\mathcal{R} \equiv \cap_{i=1}^{n} \mathcal{R}_{i} \ni R^{*}$.

Let $\left\{R^{l}\right\}$ be an increasing sequence in $\mathcal{R}$ that converges to $R^{*}$. Then the sequence $e_{i}^{l}=h_{i}\left(R^{l}\right)$ is also an increasing sequence for each $i$, which converges to $e_{i}^{*}$.

Since $\Gamma$ is credible, and each $e_{i}^{l}<e_{i}^{*}$, it must be that:

$$
\text { for all } l, \sum_{i} \sigma_{i}\left(R^{l}\right)+\theta\left(R^{l}\right)=R^{l}
$$

and

$$
\text { for all } i, l, u_{i}\left(\sigma_{i}\left(R^{l}\right)\right)+m_{i}\left(\theta\left(R^{l}\right)\right)<u_{i}\left(x_{i}^{*}\right)+m_{i}\left(y^{*}\right) \equiv \pi_{i}
$$

Given (5) and (31), it follows that the sequence $\left\{\theta\left(R^{l}\right)\right\}$ is bounded below by 0 and above by $R^{*}-\sum \underline{x}_{i}$. The sequences $\left\{\sigma_{i}\left(R^{l}\right)\right\}$ are similarly bounded, and so each of these much have a convergent subsequence. We can therefore without loss of generality take $\left\{x_{i}^{l}\right\},\left\{y^{l}\right\}$ to be sequences which converge to $\bar{x}_{i}, \bar{y}$ respectively, with the corresponding $\left\{e_{i}^{l}\right\},\left\{R^{l}\right\}$ still converging to $e_{i}^{*}, R^{*}$. Since $\sum_{i} x_{i}^{l}+y^{l}=R^{l}$ for every $l$, and $R^{l} \nearrow R^{*}$ and addition is continuous, it follows that $\sum_{i} \bar{x}_{i}+\bar{y}=R^{*}$ also.

Claim: $(\bar{x}, \bar{y})=\left(x^{*}, y^{*}\right)$.

Proof of Claim: From (32) we know that it must be that

$$
u_{i}\left(\bar{x}_{i}\right)+m_{i}(\bar{y}) \leq u_{i}\left(x_{i}^{*}\right)+m_{i}\left(y^{*}\right) \equiv \pi_{i}, \text { for all } i
$$

Suppose that this holds as a strict inequality for some $i$. The credibility of $\Gamma$ implies that for all $l$,

$$
\left(x^{l}, y^{l}\right) \in O\left(R^{l}\right)
$$


By Lemma 1 above, $O()$ is a closed correspondence, so the fact that $\left(x^{l}, y^{l}\right) \in O\left(R^{l}\right)$ for all $l$ and $\left(x^{l}, y^{l}, R^{l}\right) \rightarrow\left(\bar{x}, \bar{y}, R^{*}\right)$ implies that $(\bar{x}, \bar{y}) \in$ $O\left(R^{*}\right)$. This implies then that (33) must hold as an equality for all $i$.

[If none of the team members care about $y$, then the efficient allocations have $y=0$ for every value of $R$. The argument above implies that $u_{i}\left(\bar{x}_{i}\right) \leq$ $u_{i}\left(x_{i}^{*}\right)$ and therefore $\bar{x}_{i} \leq x_{i}^{*}$ for all $i$, and the continuity of addition implies that $\sum_{i} \bar{x}_{i}=\sum x_{i}^{*}$, so necessarily $\bar{x}=x^{*}$. In what follows, we therefore assume at least one $i$ gets positive utility from $y$, and that $y^{*}>0$.]

Now, suppose that $\bar{y} \neq y^{*}$. Then it must be that for at least one $i, \bar{x}_{i} \neq x_{i}^{*}$, also. The strict concavity of the $u_{i}$ and weak concavity of the $m_{i}$ then imply that:

$$
\begin{gathered}
u_{i}\left(\bar{x}_{i}\right)-u_{i}\left(x_{i}^{*}\right) \leq u_{i}^{\prime}\left(x_{i}^{*}\right)\left(\bar{x}_{i}-x_{i}^{*}\right), \text { for all } i, \text { strictly for at least one } i, \text { and } \\
m_{i}(\bar{y})-m_{i}\left(y^{*}\right) \leq m_{i}^{\prime}\left(y^{*}\right)\left(\bar{y}-y^{*}\right), \text { for all } i .
\end{gathered}
$$

which implies that for all $i, u_{i}^{\prime}\left(x_{i}^{*}\right)\left(\bar{x}_{i}-x_{i}^{*}\right)+m_{i}^{\prime}\left(y^{*}\right)\left(\bar{y}-y^{*}\right) \geq u_{i}\left(\bar{x}_{i}\right)-$ $u_{i}\left(x_{i}^{*}\right)+m_{i}(\bar{y})-m_{i}\left(y^{*}\right)=0$, with a strict inequality for at least one $i$. Dividing by $u_{i}^{\prime}\left(x_{i}^{*}\right)>0$, yields $\bar{x}_{i}-x_{i}^{*}+\frac{m_{i}^{\prime}\left(y^{*}\right)}{u_{i}^{\prime}\left(x_{i}^{*}\right)}\left(\bar{y}-y^{*}\right) \geq 0$. Summing over $i$ yields the conclusion that $\sum_{i}\left(\bar{x}_{i}-x_{i}^{*}\right)+\bar{y}-y^{*}>0$, which is a contradiction. Hence, it must be that $\bar{y}=y^{*}$, and then, since (33) holds as an equality for all $i$, and $u_{i}^{\prime}>0$, it must also be that $\bar{x}=x^{*}$.

This completes the proof of the Claim.

If $\Gamma$ does induce $e^{*}$ as a Nash equilibrium, then it must be that, since each $R^{l} \in \mathcal{R}$, then for each $i, l$ :

$$
u_{i}\left(x_{i}^{l}\right)+m_{i}\left(y^{l}\right)-v_{i}\left(e_{i}^{l}\right) \leq u_{i}\left(x_{i}^{*}\right)+m_{i}\left(y^{*}\right)-v_{i}\left(e_{i}^{*}\right),
$$

or,

$$
u_{i}\left(x_{i}^{l}\right)-u_{i}\left(x_{i}^{*}\right)+m_{i}\left(y^{l}\right)-m_{i}\left(y^{*}\right)+v_{i}\left(e_{i}^{*}\right)-v_{i}\left(e_{i}^{l}\right) \leq 0 .
$$

However, since $u_{i}^{\prime}\left(x_{i}^{*}\right) F_{i}^{\prime}\left(e_{i}^{*}\right)=v_{i}^{\prime}\left(e_{i}^{*}\right)$ for each $i$, letting $\beta_{i} \equiv u_{i}^{\prime}\left(x_{i}^{*}\right)$, henceforth, the argument in Holmstrom implies that:

$$
u_{i}\left(x_{i}^{l}\right)-u_{i}\left(x_{i}^{*}\right)+m_{i}\left(y^{l}\right)-m_{i}\left(y^{*}\right)+\beta_{i}\left(R^{*}-R^{l}\right)+\beta_{i} o\left(e_{i}^{l}-e_{i}^{*}\right) \leq 0
$$

where $o(h) / h \rightarrow 0$ as $h \rightarrow 0$. Beyond this, since $\left(x^{l}, y^{l}\right) \rightarrow\left(x^{*}, y^{*}\right)$, we have that for all $i$, 


$$
\begin{aligned}
& u_{i}\left(x_{i}^{l}\right)-u_{i}\left(x_{i}^{*}\right)=\beta_{i}\left(x_{i}^{l}-x_{i}^{*}\right)+o\left(x_{i}^{l}-x_{i}^{*}\right), \text { and } \\
& m_{i}\left(y^{l}\right)-m_{i}\left(y^{*}\right)=m_{i}^{\prime}\left(y^{*}\right)\left(y^{l}-y^{*}\right)+o\left(y^{l}-y^{*}\right)
\end{aligned}
$$

Therefore, for all $i$ and $l$ it must be that:

$$
\beta_{i}\left(x_{i}^{l}-x_{i}^{*}\right)+o\left(x_{i}^{l}-x_{i}^{*}\right)+m_{i}^{\prime}\left(y^{*}\right)\left(y^{l}-y^{*}\right)+o\left(y^{l}-y^{*}\right)+\beta_{i}\left(R^{*}-R^{l}\right)+\beta_{i} o\left(e_{i}^{l}-e_{i}^{*}\right) \leq 0
$$

Dividing each of these by $\beta_{i}>0$, and summing over $i$ yields:

$$
\sum_{i}\left(x_{i}^{l}-x_{i}^{*}\right)+\sum_{i} \frac{m_{i}^{\prime}\left(y^{*}\right)}{\beta_{i}}\left(y^{l}-y^{*}\right)+R^{*}-R^{l}+\sum_{i} \frac{o\left(x_{i}^{l}-x_{i}^{*}\right)}{\beta_{i}}+\sum_{i} \frac{o\left(y^{l}-y^{*}\right)}{\beta_{i}}+\sum_{i} o\left(e_{i}^{l}-e_{i}^{*}\right) \leq 0
$$

Since $\sum_{i} \frac{m_{(}^{\prime}\left(y^{*}\right)}{\beta_{i}}=1$ and $\sum_{i} x_{i}^{l}+y^{l}=R^{l}$, this implies that

$$
(n-1)\left(\dot{R}^{*}-R^{l}\right)+\sum_{i} \frac{o\left(\sigma_{i}\left(R^{l}\right)-x_{i}^{*}\right)}{\beta_{i}}+\sum_{i} \frac{o\left(\theta\left(R^{l}\right)-y^{*}\right)}{\beta_{i}}+\sum_{i} o\left(h_{i}\left(R^{l}\right)-e_{i}^{*}\right) \leq 0
$$

must hold for all $l$. However, for large enough $l$ this will be dominated by the term $(n-1)\left(R^{*}-R^{l}\right)$, which is positive if $n>1$, and so we have a contradiction.

The following is useful in the proof of Proposition 2.

Definitions: Given any $\bar{x}_{1}>0$, let $A^{1}(R)=A(R) \cap\left\{(x, y) \mid x_{1} \leq \bar{x}_{1}\right\}$ and $O^{1}(R)$ be defined as is $O(R)$, with $A^{1}(R)$ replacing $A(R)$. Similarly, given any $\bar{y}>0$, let $A^{y}(R)=A(R) \cap\{(x, y) \mid \bar{y} \leq y\}$, and $O^{y}(R)$ be defined analogously. Then the Corollary below follows readily from this Lemma.

Lemma 2: Both $O^{1}(R)$ and $O^{y}(R)$ are closed correspondences.

Proof: For $O^{y}(R)$, it is enough to note that the fact that 0 was the lower bound on feasible $y$ values played no role in the proof, hence substituting in some $\bar{y}>0$ does not change it.

For $O^{1}(R)$, an upper bound on $x_{1}$ now exists. There is only one point in the proof at which this could matter, and that is in the construction of the $\left(x^{a}, y^{a}\right)$ that Pareto dominates $\left(x^{\circ}, y^{\circ}\right)$. Suppose then that $V_{1}\left(x_{1}(\lambda), y(\lambda)\right)=$ $V_{1}\left(x_{1}^{o}, y^{\circ}\right)$. If this is because $x_{1}^{o}=x_{1}^{1}=\underline{x}$, then there is no problem in letting $x_{1}^{a}$ be as defined in the Lemma. However, if this is because $x_{1}^{\circ}=x_{1}^{1}=x_{1}(\lambda)=$ 
$\bar{x}_{1}$, then it must be that $x_{1}^{k} \leq x_{1}^{o}$ for all $k$. We can let $x_{1}^{a}=x_{1}(\lambda)$, and if $m_{1}^{\prime}>0$, then $V_{1}\left(x_{1}^{a}, y^{a}\right)>V_{1}\left(x_{1}^{o}, y^{o}\right)$ and the proof goes through. If $m_{1}^{\prime} \equiv 0$ then $V_{1}\left(x_{1}^{k}, y^{k}\right) \leq V_{1}\left(x_{1}^{o}, y^{o}\right)=V_{1}\left(x_{1}^{a}, y^{a}\right)$ for all $k$, and again the proof goes through.

Proof of Proposition 2: (i) Suppose that $a^{1}$ is as stated in the Proposition, that $R^{1}=f\left(e^{1}\right)$, and that, by way of contradiction, $\Gamma=\langle\sigma, \theta\rangle$ satisfies (22), is credible, and that $e^{1}$ is a Nash equilibrium of the game $\Gamma$ induces. The method used in the Proof of Proposition 1 above can again be used to create a sequence, $\left\{b^{l}\right\}=\left\{x^{l}, y^{l}, e^{l}, R^{l}\right\}$ such that:

- $R^{l}$ is an increasing sequence that converges to $R^{1}$

- each $e_{i}^{l}$ is an increasing sequence that converges to $e_{i}^{1}$

- $\left(x^{l}, y^{l}\right) \in O^{1}\left(R^{l}\right)$ for all $l$.

- $\left(x^{l}, y^{b}\right)$ converges to some $\left(x^{o}, y^{\circ}\right)$.

By Lemma 2, then, it must be that $\left(x^{o}, y^{o}\right) \in O\left(R^{1}\right)$, also. Just as in the proof of Proposition 1, we have:

Claim: $\left(x^{0}, y^{\circ}\right)=\left(x^{1}, y^{1}\right)$

Proof of Claim: The proof follows that in Proposition 1, until we arrive at the fact that for all $i$,

$$
u_{i}^{\prime}\left(x_{i}^{1}\right)\left(x_{i}^{o}-x_{i}^{1}\right)+m_{i}^{\prime}\left(y^{1}\right)\left(y^{\circ}-y^{1}\right) \geq u_{i}\left(x_{i}^{o}\right)-u_{i}\left(x_{i}^{1}\right)+m_{i}\left(y^{o}\right)-m_{i}\left(y^{1}\right)=0
$$

with a strict inequality holding for at least one $i$. We can divide the left-hand expression for all $i \neq 1$ by $u_{i}^{\prime}\left(x_{i}^{1}\right)>0$, and divide that for $i=1$ by $u_{1}^{\prime}\left(x_{1}^{1}\right)+\delta>0$, and sum over all $i$ to get:

$\frac{u_{1}^{\prime}\left(x_{1}^{1}\right)}{u_{1}^{\prime}\left(x_{1}^{1}\right)+\delta}\left(x_{1}^{\circ}-x_{1}^{1}\right)+\sum_{i=2}^{n}\left(x_{i}^{o}-x_{i}^{1}\right)+\left[\frac{m_{1}^{\prime}\left(y^{1}\right)}{u_{1}^{\prime}\left(x_{1}^{1}\right)+\delta}+\sum_{i=2}^{n} \frac{m_{i}^{\prime}\left(y^{1}\right)}{u_{i}^{\prime}\left(x_{i}^{1}\right)}\right]\left(y^{o}-y^{1}\right)>0$

and, using (25), and the fact that both allocations are in $O\left(R^{1}\right)$, this reduces to:

$$
\frac{u_{1}^{\prime}\left(x_{1}^{1}\right)}{u_{1}^{\prime}\left(x_{1}^{1}\right)+\delta}\left(x_{1}^{o}-x_{1}^{1}\right)+\left(x_{1}^{1}-x_{1}^{o}\right)>0
$$

or,

$$
\left(\frac{u_{1}^{\prime}\left(x_{1}^{1}\right)}{u_{1}^{\prime}\left(x_{1}^{1}\right)+\delta}-1\right)\left(x_{1}^{o}-x_{1}^{1}\right)>0
$$


Claim.

and since $\delta \leq 0$, and $x_{1}^{o} \leq x_{1}^{1}=\bar{x}_{1}$, this cannot be. This proves the

Again, since each $R^{l} \in \mathcal{R}$, it follows that

$$
W_{i}\left(a_{i}^{l}\right) \leq W_{i}\left(a_{i}^{1}\right)
$$

for all $i$ and for all $l$, which can be re-written as:

$$
u_{i}\left(x_{i}^{l}\right)-u_{i}\left(x_{i}^{1}\right)+m_{i}\left(y^{l}\right)-m_{i}\left(y^{1}\right)+v_{i}\left(e_{i}^{1}\right)-v_{i}\left(e_{i}^{l}\right) \leq 0 .
$$

Now, letting $u_{i}^{\prime}\left(x_{i}^{1}\right)=\beta_{i}$ for $i \neq 1$ and $u_{1}^{\prime}\left(x_{1}^{1}\right)+\delta=\beta_{1}$, and using the same logic as in the proof of Prop. 1, we have that for all $l$;

$$
(n-1)\left(R^{1}-R^{l}\right)+\left(\frac{u_{1}^{\prime}\left(x_{1}^{1}\right)}{\beta_{1}}-1\right)\left(x_{1}^{l}-x_{1}^{1}\right)+\sum_{i}\left[\frac{o\left(\sigma_{i}\left(R^{l}\right)-x_{i}^{1}\right)}{\beta_{i}}+\frac{o\left(\theta\left(R^{l}\right)-y^{*}\right)}{\beta_{i}}+o\left(h_{i}\left(R^{l}\right)-\right.\right.
$$

Now, divide the sequence $\left\{b^{l}\right\}$ into two subsets, $B_{0}=\left\{b^{l} \mid x_{1}^{l}=x_{1}^{1}=\bar{x}_{1}\right\}$, and $B_{1}=\left\{b^{l} \mid x_{1}^{l}<\bar{x}_{1}\right\}$. At least one of these subsequences must still converge to $\left(a^{1}, R^{1}\right)$, and perhaps both do, and for both subsequences, (34) must hold for all $l$. If the subsequence $B_{0}$ converges, then the second term in (34) is zero for every $l$ such that $b^{l} \in B_{0}$, and the argument of Prop. 1 results in a contradiction. If the subsequence $B_{1}$ converges, then since the constraint $\sigma_{1}\left(R^{l}\right) \leq \bar{x}_{1}$ is not binding, each element of $B_{1}$ is such that $\left(x^{l}, y^{l}\right) \in O\left(R^{l}\right)$, the unconstrained ex-post efficient set. Since $O()$ is a closed correspondence, by Lemma 1 , then in fact $\left(x^{1}, y^{1}\right) \in O\left(R^{1}\right)$ which means that,

$$
\sum_{i=1}^{n} \frac{m_{i}^{\prime}\left(y^{1}\right)}{u_{i}^{\prime}\left(x_{i}^{1}\right)}=1
$$

This, together with (25) imply that $\delta=0$, so that necessarily $\beta_{1}=u_{1}^{\prime}\left(x_{1}^{1}\right)$, and again the second term in (34) disappears for every $l$ such that $b^{l} \in B_{1}$, and we have a contradiction.

(ii)The proof that an $a^{r}$ that is as stated in the Proposition cannot be induced proceeds analogously to the above, and is not presented here.

\section{References}

Andolfatto, D., and E. Nosal, (1997) 'Optimal team contracts' Canadian Journal of Economics, 385-96. 
Andreoni, J., (1989) 'Giving with impure altruism: applications to charity and Ricardian equivalence; Journal of Political Economy, 1447-58.

Andreoni, J., (1990), 'Impure altruism and donations to public goods: a theory of warm-glow giving:, Economic Journal, 464-77.

Alchian, A., and Demsetz, H., (1972), 'Production, information costs, and economic organization', American Economic Review.

d'Aspremont, C. and Gerard-Varet, L.-A., (1998), 'Linear inequality methods to enforce partnerships under uncertainty: a review', Games and Economic Behavior, 311-36.

Berle, A. and G. Means, (1932) The Modern Corporation and Private Property.

Bilodeau, M. and A. Slivinski. (1998), 'Rational nonprofit entrepreneurs', The Journal of Economics and Management Strategy.

Bilodeau, M. and A. Slivinski. (1996), 'Volunteering nonprofit entrepreneurial services', Journal of Economic Behavior and Organization.

Brody, E. (1996) 'Agents without principals: the economic convergence of the nonprofit and for-profit organizational forms', New York Law School Law Review.

Coase, R., (1937), 'The nature of the firm', Economica.

Cremer, J., (1986), 'Cooperation in ongoing organizations', The Quarterly Journal of Economics, 33-49.

Dutta, P., and R. Radner, (1993), 'Moral hazard', Rochester Center for Economic Research Working Paper No. 356, forthcoming in The Handbook of Game Theory, V.3.

Easley, D., and M. O'Hara (1983), 'The economic role of the nonprofit firm: Bell Journal of Economics. 531-8.

Eswaran, M., and Kotwal, A. (1984), 'The moral hazard of budgetbreaking', Rand Journal of Economics.

Fama, E., and M. Jensen (1983), 'Separation of ownership and control', Journal of Law and Economics.

Fama, E., and M. Jensen (1983), 'Agency problems and residual claims', Journal of Law and Economics.

Grossman. H. and Hart, O. (1986), 'The costs and benefits of ownership: a theory of vertical and lateral integration', The Journal of Political Economy.

Handy, F., (1995). 'Reputation as collateral: an economic analysis of the role of trustees in nonprofits', .Vonprofit and Voluntary Sector Quarterly, 281-92 

nal.

Hansmann, H., (1980), 'The role of nonprofit enterprise', Yale Law Jour-

Hansmann, H., (1987), 'Economic theories of nonprofit organization', in Powell, W. W. (Ed. ), The Nonprofit Sector: A Research Handbook, Yale University Press.

Harbaugh, Bill (1998), ' What do gifts buy? A model of philanthropy and tithing based on prestige and warm glow', The Journal of Public Economics.

Holderness, C. G., and D.P. Sheehan (1988) 'The role of majority stockholders in publicly held corporations: an exploratory analysis, Journal of Financial Economics.

Holmstrom, B., (1982), 'Moral hazard in teams', The Bell Journal of Economics.

Holmstrom, B. and Milgrom, P.(1991), 'Multi-task principal-agent analyses: incentive contracts, asset ownership and job design', Journal of Law, Economics and Organization, 24-52.

Independent Sector(1992), Nonprofit Almanac, 1992-93: Dimensions of the independent sector, San Francisco, Jossey-Bass.

Lakdawalla, D., and T. Philipson, (1998) 'Nonprofit production and competition', NBER Working Paper 637\%.

Legros, P. and S. Matthews, (1993), 'Efficient and nearly efficient partnerships' Review of Economic Studies, 60, 599-612.

Legros, P. and H. Matsushima, (1991), 'Efficiency in partnerships', Journal of Economic Theory, 55, 296-322.

Radner, R., R. Myerson and E. Maskin, (1986), 'An example of a repeated partnership game with uniformly inefficient equilibria', Review of Economic Studies, 53, 59-70.

Roomkin, M., and B. Weisbrod, (1994), 'Managerial compensation in for-profit and nonprofit hospitals: is there a difference?, Draft, Northwestern $\mathrm{U}$.

Rose-Ackerman, S., (1996) 'Altruism, nonprofits, and economic theory', Journal of Economic Literature, 701-728.

Simon, J. G., (1987), 'The tax treatment of nonprofit organizations: a review of federal and state policies', in Powell, W.W. (Ed.), The Nonprofit Sector: A Research Handbook, Yale University Press.

Slivinski, A. and R. Steinberg, (1998), 'Soliciting the warm glow: an economic model of fund-raising', typescript.

Slivinski, A., (1999), 'Team incentives with stochastic output', manuscript, University of Western Ontario. 
U.S. Department of Commerce, Bureau of the Census(1989), 1987 census of service industries, Washington, DC: U.S. GPO.

Weisbrod, B., (1983), 'Nonprofit and proprietary sector behavior: wage differentials among lawyers', Journal of Labor Economics, 246-63.

Williams, S., and Radner, R., (1995), 'Efficiency in partnerships when the joint output is uncertain' in The Economics of Decentralization: Complexity, Efficiency, and Stability. Essays in Honor of Stanley Reiter. Kluwer,Boston. 